\title{
Malignant Lymphoma, Non-Cleaved, Diffuse
}

National Cancer Institute

\section{Source}

National Cancer Institute. Malignant Lymphoma, Non-Cleaved, Diffuse. NCI Thesaurus. Code C27266.

Antiquated term for diffuse non-Hodgkin lymphomas composed of non-cleaved cells.

The vast majority of cases are mature B-cell lymphomas (Burkitts or diffuse large B-cell lymphomas).--2004 